\title{
Adult colouring: the effect of app-based vs. pen-and-paper colouring on mindfulness and anxiety
}

\section{BACKGROUND}

The rise in popularity of "mindfulness colouring books" has led to the development of colouring applications as an alternative to the traditional pen-and-paper versions. There have been no investigations exploring these applications in regards to mindfulness.

\section{PARTICIPANTS AND PROCEDURE}

In two randomised experiments, this study examined whether there were any differences in state mindfulness and anxiety between (a) paper-and-pen and a colouring application (i.e., Experiment 1; $n=100$ ), and (b) two different methods of colouring within an application (i.e., tapping or swiping; i.e., Experiment $1 ; n=100$ ).

\section{RESULTS}

Experiments 1 and 2 showed a significant decrease in anxiety symptoms following a single colouring session, irre- spective of different conditions. Also, Experiment 1, but not Experiment 2, revealed that colouring through the application significantly aided the increase in mindfulness.

\section{CONCLUSIONS}

App-based colouring may be a contemporary time- and cost-effective intervention in reducing anxiety. However, the non-significant increase in mindfulness appears challenging when attempting to justify the results. The effectiveness of colouring apart from mindfulness is seen through potential constructs such as flow, and display a limitation that requires further reflections on guidance to enhance mindfulness through colouring. Future directions are discussed.

\section{KEY WORDS}

anxiety; mindfulness; colouring/colouring books; mandala; colouring applications

ORGANIZATION - Birmingham City University, Birmingham, United Kingdom

AUthors' Contributions - A: Study design - B: Data collection - C: Statistical analysis - D: Data interpretation .

E: Manuscript preparation · F: Literature search · G: Funds collection

Corresponding Author - Michail Mantzios, Ph.D., Birmingham City University, The Curzon Building Room C307,

B4 7BD Birmingham, United Kingdom, e-mail: michael.mantzios@bcu.ac.uk

to Cite this ARticle - Mantzios, M., Hussain, H., Hussain, A., Egan, H., \& Scanlon, P. (2019). Adult colouring: the effect

of app-based vs. pen-and-paper colouring on mindfulness and anxiety. Health Psychology Report. https://doi.org/

10.5114/hpr.2019.87312

RECEIVED 19.06.2019 · REVIEWED 29.07.2019 • ACCEPTED 29.07.2019 • PUBLISHED 14.08.2019 


\section{BACKGROUND}

Mindfulness is a conscious state of being attentive and aware of the present moment, while upholding a non-judgemental attitude, which is usually practiced through meditation (Baer, 2006; Bishop, 2004; Kabat-Zinn, 2003). There are several programmes that have been developed, such as MindfulnessBased Stress Reduction (MBSR; Kabat-Zinn, 1982), Mindfulness-Based Cognitive Therapy (MBCT; Segal, Williams, \& Teasdale, 2002), as well as mindfulness informed Dialectical Behaviour Therapy (DBT; Linehan, 1993), and Acceptance and Commitment Therapy (ACT; Hayes, Strosahl, \& Wilson, 1999). These programmes include different practices such as mindfulness breathing meditation, the body scan, and other practices. The growing interest and popularity in mindfulness practices (see Mantzios \& Giannou, 2018b) brought about similarly popular mindfulness colouring books, usually focused on mandala designs (circular abstract patterns - Blevins, 2011). Colouring books represent an alternative practice of mindfulness (rather than using mindfulness meditation), and may suit individuals who find it difficult to meditate when they are novices to such practices. Nevertheless, mindfulness guidance and ongoing instructions are not present in most research investigating colouring, making it hard to justify whether it represents a mindful practice or whether there are other underlying elements that may be responsible for the positive findings (see Mantzios \& Giannou, 2018a). Considerable research around colouring books and/ or mindfulness has focused on the reduction of anxiety, while aiding people who are in need has not been as straight forward as expected.

The pressing need for additional effective interventions for anxiety is clear, especially when considering the concomitant financial impact on health care systems, and the corresponding increased use of healthcare provision (Andlin-Sobocki \& Wittchen, 2005; Stein, Hollander, \& Rothbaum, 2010). Treatment for anxiety is often pharmacological (Martin-Merino, Ruigomez, Wallander, Johansson, \& Garcia-Rodriguez, 2009), but the side effects can be debilitating and contribute to poor adherence (Kirsch et al., 2008). Furthermore, high relapse rates and small treatment effects have been widely observed, highlighting the need for additional interventions (Hofmann \& Mathew, 2008; Hollon, Stewart, \& Strunk, 2006). Within the British National Health Service (NHS), individuals are currently facing many barriers to access the available treatments (commonly cognitive-behavioural therapy and psychopharmacology). Meanwhile systematic reviews and meta-analyses demonstrate that mindfulness interventions significantly assisted the reduction of anxiety among clinical and non-clinical populations (Strauss, Cavanagh, Oliver, \& Pettman, 2014; Vøllestad, Nielsen, \& Nielsen, 2012) and aided the reduction of anxiety symptoms (Gotink, Meijboom, Vernooij, Smits, \& Hunink, 2016). Considering the simplicity of use and low cost, as well as immediate availability of colouring books and corresponding applications, associating effective colouring books and mindfulness may be a significant step towards public mental health and mental illness prevention.

The literature on colouring interventions has been investigated as a mechanism to reduce anxiety, but has produced mixed results. Curry and Kasser (2005) found colouring to be an effective mechanism for reducing anxiety. In their study, participants were asked to write about a fearful experience as a method of inducing anxiety, and were allocated to one of three conditions: a plaid design (i.e., a checkers design), free drawing or colouring a mandala condition. Anxiety levels were measured before and after the colouring task. The results indicated a significantly greater reduction in anxiety of participants assigned to the mandala colouring and plaid design in comparison to the free drawing participants. Van der Vennet and Serice (2012) replicated Curry and Kasser's (2005) research and found that the mandala design produced a significant reduction in anxiety, but not in the plaid or free drawing condition. Inconsistent findings continued to appear in the academic literature, where plaid designs displayed higher effectiveness in reducing anxiety over mandala colouring designs (Drake, Searight, \& Olson-Pupek, 2014), while non-induction of anxiety at the start of the experiment showed that colouring did not aid anxiety reduction as expected (Small, 2006). Importantly, however, while Curry and Kasser (2005) and Carsley, Heath, and Fajnerova (2015) speculated a mindfulness rationale and theory behind the therapeutic effect of mandala colouring books, they did not investigate mindfulness changes in their research (see also Drake et al., 2014; Carsley et al., 2015).

Flett and colleagues (2017) were among the first to investigate colouring and the potential change in mindfulness levels. In their research, colouring significantly lowered anxiety and depressive symptoms when compared to logic puzzles (as a control condition), but mindfulness increased in both colouring and control conditions. While the results were clear in terms of mental health, the interpretation of mindfulness having a mediating effect (or explaining the results) on the relationship between colouring and mental health was weak. Carsley and Heath (2018a) in an attempt to explore potential colouring book applications in adolescent educational settings, compared a mandala with a free-drawing activity and found a significant decrease in test anxiety and increase in mindfulness after both activities. A similar experiment was conducted with children, where Carsley and Heath (2018b) obtained comparable results, and shed light on individual differences when 
accounting for dispositional mindfulness when investigating such interventions. In contrast, Mantzios and Giannou (2018a) obtained similar results, where mandala colouring did not increase mindfulness over free drawing, and in a second experiment suggested that mindfulness guidance would be the only way of colouring being a mindful activity. While their findings showed a significant increase in mindfulness and decrease in anxiety, their methodology significantly differed from the traditional unguided colouring research by incorporating ongoing mindfulness colouring guidance. Mantzios and Giannou (2018a) argued that mandala colouring books are not 'mindfulness colouring books' and do not represent a mindfulness practice as usually instructed in meditation, and proposed that unless there is some integration of mindfulness meditation guidance that is adjusted to colouring, there is no way to determine the underlying mechanisms of colouring books. We explain these past results by suggesting that any activity could be a mindfulness practice, depending on the general demeanour and personalities that are displayed by participants. For example, a participant who displays higher scores in trait mindfulness (rather than lower scores in trait mindfulness) may use everyday activities in mindful ways, which may imitate the way one formally practices mindfulness (e.g., Hanley, Warner, Dehili, Canto, \& Garland, 2015; Mantzios \& Wilson, 2014). Similarly, an individual who is naturally more anxious may use colouring as a time to reflect on deadlines that are coming up at work, the financial uncertainty that Brexit might bring about, and the need to go more frequently to the gym. Controlling for individual differences may be an element that requires further consideration to ensure whether logic puzzles and/or mandala colouring (without mindfulness guidance) are mindfulness practices, and whether they assist or hinder anxiety reduction.

\section{THE PRESENT STUDIES}

This work adds to existing knowledge by exploring colouring applications, as past research so far has focused on traditional pen and paper colouring. Colouring applications are readily available and may form a cost-effective and valuable addition to approaches in anxiety prevention and reduction. While some literature has indicated that only physically colouring on paper can enhance well-being (Dredge, 2015; Vagino, 2015), exploring colouring apps may further inform on the benefits for mental health and prevention. Therefore, in a randomised experiment, this research aimed to examine any variation in state mindfulness and anxiety between pen and paper and application colouring conditions.

In a second randomised experiment, the functions of colouring apps were explored in more detail. The way someone colours in applications differs, where one can simply tap a specific area within the mandala design to colour it, or use the finger in a swipe mode to colour, which requires multiple movements to colour a specific area. As no other research has been conducted in the area, we assumed that swiping assimilates the traditional pen-and-paper colouring movements, and requires more focus and attention to colour within the lines, both of which may be closer to a more mindful and focused practice that centres on the present moment. Therefore, the second aim was to explore whether colouring techniques (i.e., swiping vs. tapping to colour in) would display differences in state anxiety and mindfulness levels.

\section{EXPERIMENT 1}

\section{PARTICIPANTS AND PROCEDURE}

\section{PARTICIPANTS}

University students within the West Midlands region of the United Kingdom were recruited $(n=100)$ based on an opportunity sample, and participants were randomly allocated to either the paper colouring $(n=50)$ or application colouring condition $(n=50)$. The mean age of participants was $21.9(S D=5.17)$, which ranged from 18 to 51 years old, with varied male $(n=29)$ and female participant numbers $(n=71)$. Recruitment of participants was voluntary and did not involve any incentives or any type of reward. Cohen's (1992) guidelines were consulted in an attempt to achieve a medium effect size, and a minimum of 37 participants were required for each condition (total suggested $n=74$; Cohen, 1992).

\section{MATERIALS}

Colouring Materials. The Calmeleon application is an online colouring book application, which includes different mandala designs, colours and different colouring functions. The functions to colour in the spaces include the option to colour by tapping and physically moving a finger across the colouring spaces by swiping. For this condition, in an attempt to imitate the traditional pen-and-paper versions of colouring, the swiping function was selected. Both groups were given the same mandala design from the Calmeleon application on an Apple iPad device and participants were exposed to the same 10 basic colours available. These colours were red, blue, green, yellow, purple, orange, pink, black, grey and brown. Materials also included an email from the application developer, giving permission to use the application for research purposes. The pen and paper condition matched the
Adult colouring app, mindfulness, and anxiety 
Michail Mantzios, Hafsah Hussain, Amirah Hussain, Helen Egan, Paraic Scanlon application page, colours used and time spent on the colouring activity.

The State Anxiety Inventory (SAI; Marteau \& Bekker, 1992). The State Anxiety Inventory measures levels of anxiety by assessing the responses from six items. The calculation of scores consisted of responses which are retrieved from a range of four options from the Likert scale, varying from 1 (not at all) to 4 (very much), with scores ranging from 6 to 20 . Example items include: "I feel tense" and "I am relaxed". Higher scores on the SAI illustrate higher levels of anxiety. The present study produced a Cronbach's $\alpha$ of $.89 / .87$ for pre- and post-measurements.

The State Mindfulness Scale (SMS; Tanay \& Bernstein, 2013). The State Mindfulness Scale comprises 21 items and uses a five-point Likert scale that assesses mindfulness by measuring awareness of the present moment. Replies range from 1 (not at all) to 5 (very well), with scores ranging from 21 to 105. Example items include: "I tried to pay attention to pleasant and unpleasant sensations" and "I noticed many small details of my experience". Higher scores demonstrate higher levels of mindfulness and therefore increased feelings of awareness. The State Mindfulness Scale has demonstrated consistent results of increased test-retest reliability (e.g., mean $r=.59-.68$, $p=.01$; see Tanay \& Bernstein, 2013). The present study produced an $\alpha$ of $.95 / .94$ for pre- and postcolouring. The mindfulness scale included body and mind subscales and these two subscales loaded on two factors, one reflecting state mindfulness of bodily sensations and the other of mental events (such as emotions and patterns of thought - see Tanay \& Bernstein, 2013 for review). The body subscale produced a Cronbach's $\alpha$ of .81/.78 and the mind subscale produced an $\alpha$ of .92/.93 for pre- and post-colouring.

\section{PROCEDURE}

Ethical approval was obtained from the ethical board within the university and this study followed ethical practices in accordance with the British Psychological Society. Additionally, permission was granted from the application publishers for the application to be used by the corresponding author for research purposes.

Participants were recruited on campus using opportunity sampling, and were invited to a laboratory study where they were tested in isolation. All participants were informed that the study was investigating the effects of colouring. The consent, general information and demographics forms were administered concurrently to all participants through Google forms. Participants were asked to record a random number allocated to their data to maintain anonymity. The two pre-assessment scales were administered first. Next, participants coloured the mandala on either the application or a paper copy for 10 minutes, and once finished colouring, the researcher administered the two scales again.

\section{STATISTICAL ANALYSIS}

This study used a 2 (colouring: application, paper) x 2 (time: pre, post) mixed design ANOVA to examine both state anxiety and mindfulness. Follow-up analyses were conducted on the subscales for the State Mindfulness Scale.

\section{RESULTS}

An ANOVA was conducted to assess state anxiety across the two different conditions (application and paper) and between the two times (pre- and post-colouring). The results revealed a significant difference between anxiety and time, $F(1,98)=7.55, p=.007$, $\eta_{\mathrm{p}}{ }^{2}=.07$. This suggested a reduction in anxiety from pre-colouring to post-colouring. Nevertheless, there was no indication of a main effect between colouring conditions, $(p=.569)$, or of an interaction between anxiety and colouring conditions $(p=.479)$. The results suggested that there were no differences in the effect of the two colouring condition on state anxiety scores, implying that the application is similarly effective in anxiety reduction (see Table 1 for descriptive statistics).

\section{Table 1}

State anxiety score means (M), standard deviation (SD), number of participants $(n)$ and $95 \%$ confidence intervals $( \pm 1.96 * S D)$ for colouring conditions across two time periods

\begin{tabular}{|c|c|c|c|c|c|c|c|}
\hline \multirow[t]{2}{*}{$\begin{array}{l}\text { Colouring } \\
\text { condition }\end{array}$} & \multirow[t]{2}{*}{$\begin{array}{l}\text { Number of } \\
\text { participants } \\
(n)\end{array}$} & \multirow[t]{2}{*}{$\begin{array}{l}\text { Pre-anxiety } \\
\text { scale } M(S D)\end{array}$} & \multicolumn{2}{|c|}{$\begin{array}{c}95 \% \text { confidence } \\
\text { intervals for mean } \\
\text { pre-anxiety }\end{array}$} & \multirow[t]{2}{*}{$\begin{array}{l}\text { Post-anxiety } \\
\text { scale } M(S D)\end{array}$} & \multicolumn{2}{|c|}{$\begin{array}{c}95 \% \text { confidence } \\
\text { intervals for mean } \\
\text { post-anxiety }\end{array}$} \\
\hline & & & Lower & Upper & & Lower & Upper \\
\hline Application & 50 & $14.00(4.13)$ & 12.82 & 15.17 & $13.14(3.85)$ & 12.04 & 14.23 \\
\hline Paper & 50 & $13.90(4.62)$ & 12.58 & 15.21 & $12.44(3.69)$ & 11.39 & 13.48 \\
\hline
\end{tabular}


Table 2

State mindfulness scores mean (M), standard deviation (SD), number of participants (n) and 95\% confidence intervals $\left( \pm 1.96{ }^{*} S D\right)$, for application colouring and paper colouring across two time periods

\begin{tabular}{|c|c|c|c|c|c|c|c|}
\hline \multirow[t]{2}{*}{$\begin{array}{l}\text { Colouring } \\
\text { condition }\end{array}$} & \multirow[t]{2}{*}{$\begin{array}{l}\text { Number of } \\
\text { participants } \\
(n)\end{array}$} & \multirow[t]{2}{*}{$\begin{array}{l}\text { Pre-mind- } \\
\text { fulness scale } \\
\qquad M(S D)\end{array}$} & \multicolumn{2}{|c|}{$\begin{array}{l}95 \% \text { confidence } \\
\text { intervals for mean } \\
\text { pre-mindfulness }\end{array}$} & \multirow[t]{2}{*}{$\begin{array}{l}\text { Post-mind- } \\
\text { fulness } \\
\text { scale } M(S D)\end{array}$} & \multicolumn{2}{|c|}{$\begin{array}{l}95 \% \text { confidence } \\
\text { intervals for mean } \\
\text { post-mindfulness }\end{array}$} \\
\hline & & & Lower & Upper & & Lower & Upper \\
\hline Application & 50 & $62.08(16.32)$ & 57.44 & 66.71 & $71.72(15.38)$ & 67.35 & 76.08 \\
\hline Paper & 50 & $72.82(13.81)$ & 68.89 & 76.74 & $74.56(16.28)$ & 69.93 & 79.18 \\
\hline Total & 100 & 67.45 (15.99) & & & $73.14(15.82)$ & & \\
\hline
\end{tabular}

Table 3

State mindfulness mind and body subscale scores mean (M) and standard deviation (SD) for application colouring and paper colouring across two time periods

\begin{tabular}{lcccc}
\hline $\begin{array}{l}\text { Colouring } \\
\text { condition }\end{array}$ & $\begin{array}{c}\text { Mindfulness body } \\
\text { pre-subscale } M(S D)\end{array}$ & $\begin{array}{c}\text { Mindfulness body } \\
\text { post-subscale } M(S D)\end{array}$ & $\begin{array}{c}\text { Mindfulness mind } \\
\text { pre-subscale } M(S D)\end{array}$ & $\begin{array}{c}\text { Mindfulness mind } \\
\text { post-subscale } M(S D)\end{array}$ \\
\hline Application & $14.60(4.43)$ & $18.02(3.76)$ & $41.58(10.75)$ & $47.14(10.66)$ \\
Paper & $16.90(3.62)$ & $18.72(3.97)$ & $48.50(9.51)$ & $49.14(11.32)$ \\
\hline
\end{tabular}

A second ANOVA was conducted to assess state mindfulness across the two different conditions (application and paper) and between the two times (precolouring and post-colouring - see Table 2 for descriptive statistics). The results showed a significant difference in time, $F(1,98)=14.42, p=.001, \eta_{\mathrm{p}}{ }^{2}=.13$. A significant main effect was also observed between colouring conditions $\left(F(1,98)=6.28, p=.014, \eta_{\mathrm{p}}{ }^{2}=.06\right)$, with a significant interaction between mindfulness and colouring conditions $(F(1,98)=6.94, p=.010$, $\left.\eta_{\mathrm{p}}^{2}=.07\right)$. The results indicate that those who used the application reported a significantly higher increase in state mindfulness than those who coloured with pen and paper.

Further post-hoc tests were conducted to explore differences in body and mind subscales, in a further attempt at acquiring more information around psychological and physiological manifestations of mindfulness. Mixed ANOVAs were conducted on colouring conditions (i.e., application and paper) and time (i.e., pre-, post-) for mindfulness subscales (see Table 3 for descriptive statistics). The results showed a significant difference between times, $\left(F(1,98)=42.42, p=.001, \eta_{\mathrm{p}}^{2}=.30\right)$, and a significant main effect for colouring conditions $(F(1,98)=4.82$, $\left.p=.030, \eta_{\mathrm{p}}^{2}=.05\right)$. The interaction between the mindfulness body subscale and colouring conditions was marginally non-significant $(F(1,98)=3.95, p=.050$ (i.e., $\left.p=0.050000003), \eta_{\mathrm{p}}{ }^{2}=.04\right)$. There was also a significant difference between times $(F(1,98)=8.82$, $p=.004, \eta_{\mathrm{p}}^{2}=.08$ ), a significant main effect for colouring conditions when observing the mindfulness mind subscale $\left(F(1,98)=5.86, p=.017, \eta_{\mathrm{p}}^{2}=.06\right)$, and a significant interaction between the mindfulness mind subscale and colouring conditions $(F(1,98)=5.55$, $\left.p=.020, \eta_{\mathrm{p}}{ }^{2}=.05\right)$. Together the results suggested a difference in the effectiveness of application colouring and paper colouring on mindfulness mind and body subscales, whereby the application performed better across cognitive/affective (i.e., mind subscale) and physiological (i.e., body subscale) dimensions of mindfulness.

Other variables recorded during the colouring stage were tested as covariates, or for the possibility of external conditions affecting the outcome of the study. These included the amount of colours changed and the time taken to change colours. None of these variables significantly affected the results, or showed a significant difference between groups, and were therefore excluded from any further analyses.

\section{EXPERIMENT 2}

\section{PARTICIPANTS AND PROCEDURE}

\section{PARTICIPANTS}

An opportunity sample of 100 (female $n=70$ ) university students within the West Midlands region of the United Kingdom recruited through the research participation scheme took part and were randomly assigned to either the tap condition $(n=50)$ or the swiping condition $(n=50)$. Participant's age ranged from
Adult colouring app, mindfulness, and anxiety 
18 to $51(M=21.67, S D=5.13)$. Similar to Experiment 1 , to achieve a medium effect size $\left(d \geq 0.5, \eta_{\mathrm{p}}{ }^{2}=.09\right)$ a minimum of 37 participants were required for each condition (total suggested $n=74$; Cohen, 1992).

\section{MATERIALS}

Colouring Materials. The Calmeleon colouring application was used, where functions to colour in the spaces defined the actual conditions participants were allocated to and included the option to colour by tapping versus swiping (as described in Experiment 1).

State Mindfulness Scale (SMS; Tanay \& Bernstein, 2013). The SMS was used and Cronbach's $\alpha$ was $.94 / .95$ for pre- and post-colouring measurements. The mindfulness scale included body and mind subscales. Cronbach's $\alpha$ for the mindfulness body subscale was .76/.81 and Cronbach's $\alpha$ for the mindfulness mind subscale was $.92 / .94$ for pre- and post-colouring measurements (see Experiment 1 for further description).

The State Anxiety Inventory (SAI; Marteau \& Bekker, 1992). The SAI was used and Cronbach's $\alpha$ was $.88 / .88$ for pre- and post-colouring measurements (see Experiment 1 for further description).

\section{PROCEDURE}

See the procedure of Experiment 1. Instead of paperand-pen colouring and swiping, the two conditions in this experiment were tapping or swiping to colour.

\section{STATISTICAL ANALYSIS}

This study employed a 2 (condition: swiping, tap) $\mathrm{x}$ 2 (time: pre, post) mixed design ANOVA to measure state anxiety and mindfulness.

\section{RESULTS}

Similar to Experiment 1, a mixed design ANOVA examined the difference between colouring techniques (i.e., tap and swiping) on participants' state anxiety at pre- and post-colouring measurements (see Table 4 for descriptive statistics). A significant difference was found for time, $F(1,98)=12.52, p=.001, \eta_{p}{ }^{2}=.11$, suggesting a decline in anxiety levels from pre- to post-colouring. There was a non-significant main effect for colouring techniques $(F(1,98)=0.10, p=.331)$ and a significant interaction between colouring techniques and anxiety $\left(F(1,98)=6.05, p=.016, \eta_{\mathrm{p}}{ }^{2}=.06\right)$. The results indicate that colouring conditions affect state anxiety scores, with participants showing a significant decrease in anxiety scores across both colouring techniques.

A second ANOVA examined the effect of colouring techniques (i.e., tap and swiping) on state mindfulness scores at pre- and post-colouring measurements. The results showed a non-significant difference in time $F(1,98)=.42, p=.517$, a non-significant main effect for colouring techniques $(F(1,98)=1.38, p=.242)$, and non-significant interaction between colouring techniques and mindfulness $(F(1,98)=3.34, p=.070)$. Despite the non-significant differences, Table 5 shows

Table 4

Number of participants (n), pre-and post-anxiety mean scores (M), standard deviations (SD) and 95\% confidence intervals $\left(\mathrm{Cl} ; \pm 1.96{ }^{*} \mathrm{SD}\right)$ for both tap and swiping colouring

\begin{tabular}{|c|c|c|c|c|c|c|c|}
\hline \multirow[t]{2}{*}{$\begin{array}{l}\text { Colouring } \\
\text { condition }\end{array}$} & \multirow{2}{*}{$\begin{array}{c}\text { Number of } \\
\text { participants } \\
(n)\end{array}$} & \multirow[t]{2}{*}{$\begin{array}{l}\text { Pre-anxiety } \\
\text { scale } M(S D)\end{array}$} & \multicolumn{2}{|c|}{$\begin{array}{c}95 \% \mathrm{Cl} \text { for mean } \\
\text { pre-anxiety }\end{array}$} & \multirow[t]{2}{*}{$\begin{array}{l}\text { Post-anxiety } \\
\text { scale } M(S D)\end{array}$} & \multicolumn{2}{|c|}{$\begin{array}{c}95 \% \mathrm{Cl} \text { for mean } \\
\text { post-anxiety }\end{array}$} \\
\hline & & & Lower & Upper & & Lower & Upper \\
\hline Tap & 50 & $13.44(3.93)$ & 12.32 & 14.55 & $12.98(3.79)$ & 12.98 & 14.05 \\
\hline Swiping & 50 & $15.16(4.63)$ & 13.84 & 16.47 & $12.60(3.75)$ & 11.53 & 13.66 \\
\hline
\end{tabular}

Table 5

State mindfulness mean scores $(M)$, number of participants $(N)$, standard deviations $(S D)$ and $95 \%$ confidence intervals $\left(\mathrm{Cl} ; \pm 1.96{ }^{*} \mathrm{SD}\right)$ for the tap and swiping colouring, across two time periods

\begin{tabular}{|c|c|c|c|c|c|c|c|}
\hline \multirow[t]{2}{*}{$\begin{array}{l}\text { Colouring } \\
\text { condition }\end{array}$} & \multirow{2}{*}{$\begin{array}{c}\text { Number of } \\
\text { participants } \\
(n)\end{array}$} & \multirow{2}{*}{$\begin{array}{l}\text { Pre-mind- } \\
\text { fulness scale } \\
\qquad M(S D)\end{array}$} & \multicolumn{2}{|c|}{$\begin{array}{l}95 \% \mathrm{Cl} \text { for mean } \\
\text { pre-mindfulness }\end{array}$} & \multirow{2}{*}{$\begin{array}{l}\text { Post-mind- } \\
\text { fulness scale } \\
M(S D)\end{array}$} & \multicolumn{2}{|c|}{$\begin{array}{l}95 \% \mathrm{Cl} \text { for mean } \\
\text { post-mindfulness }\end{array}$} \\
\hline & & & Lower & Upper & & Lower & Upper \\
\hline Tap & 50 & $71.34(15.22)$ & 67.01 & 75.66 & $69.36(18.44)$ & 64.11 & 74.60 \\
\hline Swiping & 50 & $64.76(15.93)$ & 60.23 & 69.28 & $68.92(18.57)$ & 63.64 & 74.19 \\
\hline
\end{tabular}


Table 6

Pre- and post-state mindfulness body and mind subscale mean scores (M) and standard deviations (SD) for the tap and the swiping colouring conditions

\begin{tabular}{lcccc}
\hline $\begin{array}{l}\text { Colouring } \\
\text { condition }\end{array}$ & $\begin{array}{c}\text { Mindfulness body } \\
\text { pre-subscale } M(S D)\end{array}$ & $\begin{array}{c}\text { Mindfulness body } \\
\text { post-subscale } M(S D)\end{array}$ & $\begin{array}{c}\text { Mindfulness mind } \\
\text { pre-subscale } M(S D)\end{array}$ & $\begin{array}{c}\text { Mindfulness mind } \\
\text { post-subscale } M(S D)\end{array}$ \\
\hline Tap & $16.20(3.95)$ & $16.96(4.49)$ & $48.44(10.73)$ & $46.04(12.81)$ \\
Swiping & $15.02(4.04)$ & $17.00(4.72)$ & $43.36(10.64)$ & $45.56(13.03)$ \\
\hline
\end{tabular}

how state mindfulness increased for swiping, while it decreased for tapping.

Additional post-hoc ANOVAs were conducted to explore the state mindfulness body and mind subscales (see Table 6). The mindfulness body subscale displayed a significant difference from pre- to postcolouring $\left(F(1,98)=8.49, p=.004, \eta_{p}{ }^{2}=.08\right)$, indicating an increase for both colouring techniques. A non-significant main effect for colouring techniques $(F(1,98)=0.62, p=.433)$ and a non-significant interaction between the mindfulness body subscale and colouring techniques were found $(F(1,98)=1.68$, $p=.197)$. Divergently, an additional analysis for the state mindfulness mind-subscale showed non-significant differences over time $(F(1,98)=0.01, p=.932)$, in colouring techniques when exploring the main effect $(F(1,98)=1.82, p=.180)$, and in the interaction between the mind subscale and colouring techniques $(F(1,98)=3.81, p=.054)$.

\section{DISCUSSION}

In two randomised experiments, this study explored whether (a) colouring a mandala on an application in comparison to colouring on paper increased mindfulness and decreased anxiety, and (b) colouring a mandala through swiping or tapping on design gaps of an application increased mindfulness and decreased anxiety.

The first aim of this study was to examine any variation in state mindfulness and anxiety between pen-and-paper and application colouring conditions. Outcomes demonstrated that state anxiety levels decreased significantly from pre- to post-colouring across both colouring conditions. The results were consistent with some previous literature, which revealed a reduction of anxiety after pen-and-paper mandala colouring (e.g., Sandmire, Gorman, Rankin, \& Grimm, 2012; Curry \& Kasser, 2005). Mindfulness significantly increased from pre- to post-colouring, with the application condition displaying a greater increase. Similarly, both post-hoc analyses of the mind and body subscales within the mindfulness scale mirrored these significant results. The findings are consistent with Mantzios and Giannou's (2018a) findings, where mindfulness levels were seen to increase through mandala colouring. The present findings also challenge the idea that only physically colouring on paper can enhance a therapeutic effect (Dredge, 2015; Vagino, 2015). The implications for public policy and enhancement of mental health when considering the existing use of applications and mobile devices unquestionably creates an opportunity for further research and intervention.

The second aim was to identify whether colouring techniques (swiping vs. tapping to colour in) influenced state anxiety and mindfulness levels in different ways. The findings demonstrated a significant decline in state anxiety scores from pre- to post-colouring consistent with Experiment 1 in the present study, and previous pen-and paper-literature (Chang, Schmidt, Walsh, \& Yoepp, 2005; Sandmire et al., 2012). Mindfulness scores did not significantly increase from pre- to post-colouring, while post-hoc analyses of the subscales indicated that only the mindfulness body subscale scores showed a significant difference from pre- to post-colouring. These findings are consistent with Curry and Kasser's (2005) suggestions of psychophysiological indices needing further exploration within mandala colouring and art therapies. Additionally, when anxiety similarly decreased across both techniques, the way they work for people may be fundamentally different, one being driven by mindfulness (i.e., swiping); the other potentially by immersion or any other grounding theory (discussed below through flow theory). For now, mindful experiences that relate to the mind subscale appear to be inconsistent with Experiment 1, and previous literature, reiterating the potential influence of individual differences.

Inconsistencies in findings have been variously interpreted. Mantzios and Giannou (2018a) indicated that free drawing (used as a control condition) had a similar positive effect, and did not significantly differ from mandala colouring. Therefore, despite the positive indications, the effectiveness in increasing mindfulness may require further reflection and introspection to assist the cultivation of mindfulness through mandala colouring. Labelling mandala colouring, whether it is through pen and paper or applications, as a "mindful practice" is inaccurate and
Adult colouring app, mindfulness, and anxiety 
Michail Mantzios, Hafsah Hussain, Amirah Hussain, Helen Egan, Paraic Scanlon problematic, as it suggests the existence of a practice that simulates the practices involved in mindfulness meditation, without the guidance and directions that are evident in conventional mindfulness practices (e.g., breathing meditation - see Mantzios \& Giannou, 2018a, Experiment 2). Overall, 'mandala colouring' as used in these (and other past) experiments are substantially different to 'mindfulness colouring'. On the other hand, the reality is that all conditions could potentially be mindful practices, as for some people part of mindfulness could have been achieved (i.e., present moment attention and awareness - see Brown \& Ryan, 2003) without the non-judgment attitude. This may be a precursor for another element that relates to full immersion in the task at hand that indicates flow (rather than mindfulness), and may possibly be part of the equation of successful anxiety reduction (see Csikszentmihalyi, 1990). Instead of open awareness and pivotal attentiveness of the colouring page (i.e., mindfulness), it may be full immersion in the activity (i.e., flow), which are essentially different in nature. Meanwhile, more significantly, the potential pre-existing high levels of trait mindfulness or flow may explain why it works for some people and not for others.

Evidently, this study forms the basis of future research that should explore mindfulness through means of separating the present moment attention and awareness, the presence of flow, and the potential variance of individual traits of participants. Additionally, when students are given an iPad, they report enhanced motivation towards learning (Kinash, Brand, \& Mathew, 2012). This motivation might partially explain in the current findings the use of colouring on an iPad (rather than on paper) being more effective, especially when considering different and younger age groups. Closely aligned may be the mean age of participants, which forms another element of future exploration. In a population with a wider age range, older generations might feel more familiar with traditional pen-and-paper colouring books, which may result in different outcomes.

Three possible limitations should be noted and potentially addressed in future research. First, both experiments used healthy university students, and future research may need to explore clinical samples to draw clear conclusions on the applicability of those findings. Second, the results could be interpreted more conservatively by testing the significance through a Bonferroni correction to account for the multiple comparisons, or more leniently through the Benjamini-Hochberg procedure, which would leave the majority of the statistically significant findings significant. No corrections were applied to our results, given that these experiments represent pilot studies, and should be replicated with larger and non-student populations, and used in accordance to obtain clear results. The current data will hopefully provide the drive and highlight the potential for future research in the field of colouring apps. Last, the potential of exploring individual differences as highlighted earlier should be taken into consideration, especially when considering the results of this and of previous studies with colouring interventions.

\section{CONCLUSIONS}

Overall, while the findings should be accepted with the stated limitations in mind, the use of mandala colouring books may be a suitable and cost-effective self-help practice, which could easily be embedded into educational, occupational and clinical environments to help alleviate anxiety. To create easy-to-use and cost-effective interventions that will have a sustainable impact at societal levels on wellbeing, future research should involve continuing collaboration with application developers to create evidence-based interventions. This will enable the advancement of accurate representations of mindfulness colouring interventions, while exploring underlying mechanisms that may explain the observed reduction in anxiety in mandala colouring, and any other types of colouring that are popular amongst the public.

\section{RefEREnCES}

Andlin-Sobocki, P., \& Wittchen, H. U. (2005). Cost of anxiety disorders in Europe. European Journal of Neurology, 12, 39-44. https://doi.org/10.1111/ j.1468-1331.2005.01196.x

Baer, R. (2006). Using self-report assessment methods to explore facets of mindfulness. Assessment, 13, 27-45. https://doi.org/10.1177/1073191105283504

Bishop, S. (2004). Mindfulness: A proposed operational definition. Clinical Psychology: Science and Practice, 11, 230-241. https://doi.org/10.1093/clipsy/bph077

Blevins, B. (2011). Carolyn Daitch: Anxiety Disorders: The Go-To Guide for Clients and Therapists. Journal of Child and Family Studies, 20, 706-707. https://doi.org/10.1007/s10826-011-9530-8

Brown, K. W., \& Ryan, R. M. (2003). The benefits of being present: mindfulness and its role in psychological well-being. Journal of Personality and Social Psychology, 84, 822-848. https://doi.org/10.1037/ 0022-3514.84.4.822

Carsley, D., \& Heath, N. L. (2018a). Effectiveness of mindfulness-based colouring for test anxiety in adolescents. School Psychology International, 39, 251272. https://doi.org/10.1177/0143034318773523

Carsley, D., \& Heath, N. L. (2018b). Evaluating the effectiveness of a mindfulness coloring activity for test anxiety in children. The Journal of Educational Research, 112, 143-151. https://doi.org/10.1080/002 20671.2018.1448749 
Carsley, D., Heath, N., \& Fajnerova, S. (2015). Effectiveness of a classroom mindfulness colouring activity for test anxiety in children. Journal of $A p$ plied School Psychology, 31, 239-255. https://doi.or g/10.1080/15377903.2015.1056925

Chang, C., Schmidt, L., Walsh, S., \& Yoepp, J. (2005). Lowering stress while teaching research: A creative arts intervention in the classroom. Journal of Nursing Education, 44, 330-333.

Cohen, J. (1992). A power primer. Psychological Bulletin, 112, 155-159. https://doi.org/10.1037//00332909.112.1.155

Csikszentmihalyi, M. (1990). Flow: The Psychology of Optimal Performance. New York, NY: Cambridge University Press.

Curry, N., \& Kasser, T. (2005). Can colouring mandalas reduce anxiety? Art Therapy, 22, 81-85. https:// doi.org/10.1080/07421656.2005.10129441

Drake, C. R., Searight, H. R., \& Olson-Pupek, K. (2014). The influence of art-making on negative mood states in university students. American Journal of Applied Psychology, 2, 69-72. https://doi. org/10.12691/ajap-2-3-3

Dredge, S. (2015). Adult colouring books? Inevitably, there's an app for that. The Guardian. Retrieved from www.theguardian.com/technology/2015/aug/ 27/adult-colouring-books-app-recolor

Flett, J. A. M., Lie, C., Riordan, B. C., Thompson, L. M., Conner, T. S., \& Hayne, H. (2017). Sharpen your pencils: preliminary evidence that adult coloring reduces depressive symptoms and anxiety. Creativity Research Journal, 29, 409-416. https://doi.org/ 10.1080/10400419.2017.1376505

Gotink, R. A., Meijboom, R., Vernooij, M.W., Smits, M., \& Hunink, M. M. (2016). 8-week mindfulness based stress reduction induces brain changes similar to traditional long-term meditation practice - a systematic review. Brain and Cognition, 108, 32-41. https://doi.org/10.1016/j.bandc.2016.07.001

Hayes, S. C., Strosahl, K., \& Wilson, K. (1999). Acceptance and commitment therapy: Understanding and treating human suffering. New York, NY: Guilford Press.

Hanley, A. W., Warner, A. R., Dehili, V. M., Canto, A. I., \& Garland, E. L. (2015). Washing dishes to wash the dishes: Brief instruction in an informal mindfulness practice. Mindfulness, 6, 1095-1103. https:// doi.org/10.1007/s12671-014-0360-9

Hoffman, E. J., \& Mathew, S. J. (2008). Anxiety disorders: a comprehensive review of pharmacotherapies. Mount Sinai Journal of Medicine: A Journal of Translational and Personalized Medicine, 75, 248262. https://doi.org/10.1002/msj.20041

Hollon, S., Stewart, M., \& Strunk, D. (2006). Enduring effects for cognitive behavior therapy in the treatment of depression and anxiety. Annual Review of Psychology, 57, 285-315. https://doi.org/10.1146/ annurev.psych.57.102904.190044
Kabat-Zinn, J. (1982). An outpatient program in behavioral medicine for chronic pain patients based on the practice of mindfulness meditation: Theoretical considerations and preliminary results. General Hospital Psychiatry, 4, 33-47. https://doi. org/10.1016/0163-8343(82)90026-3

Kabat-Zinn, J. (2003). Mindfulness-based interventions in context: Past, present, and future. Clinical Psychology: Science and Practice, 10, 144-156. https://doi.org/10.1093/clipsy/bpg016

Kinash, S., Brand, J., \& Mathew, T. (2012). Challenging mobile learning discourse through research: Student perceptions of Blackboard Mobile Learn and iPads. Australasian Journal of Educational Technology, 28, 639-655. https://doi.org/10.14742/ajet.832

Kirsch, I., Deacon, B., Huedo-Medina, T., Scoboria, A., Moore, T., \& Johnson, B. (2008). Initial severity and antidepressant benefits: A meta-analysis of data submitted to the Food and Drug Administration. PLoS Medicine, 5, e45. https://doi.org/10.1371/journal.pmed.0050045

Linehan, M. (1993). Cognitive-behavioral treatment of borderline personality disorder. New York, NY: Guilford Press.

Mantzios, M., \& Giannou, K. (2018a). When did colouring books become mindful? Exploring the effectiveness of a novel method of mindfulnessguided instructions for colouring books to increase mindfulness and decrease anxiety. Frontiers in Psychology, 9, 56. https://doi.org/10.3389/fpsyg.2018. 00056

Mantzios, M., \& Giannou, K. (2018b). A real-world application of short mindfulness-based practices: a review and reflection of the literature and a practical proposition for an effortless mindful lifestyle. American Journal of Lifestyle Medicine. https://doi.org/10.1177/1559827618772036

Mantzios, M., \& Wilson, J. C. (2014). Making concrete construals mindful: A novel approach of developing mindfulness and self-compassion to assist weight loss, Psychology \& Health, 29, 422-441. https://doi.org/10.1080/08870446.2013.863883

Marteau, T., \& Bekker, H. (1992). The development of a six-item short-form of the state scale of the Spielberger State-Trait Anxiety Inventory (STAI). British Journal of Clinical Psychology, 31, 301-306. https://doi.org/10.1111/j.2044-8260.1992.tb00997.x

Martin-Merino, E., Ruigomez, A., Wallander, M., Johansson, S., \& Garcia-Rodriguez, L. (2009). Prevalence, incidence, morbidity and treatment patterns in a cohort of patients diagnosed with anxiety in UK primary care. Family Practice, 27, 9-16. https://doi.org/10.1093/fampra/cmp071

NHS (2017). Generalised anxiety disorder in adults Treatment - NHS Choices. Retrieved from www. nhs.uk/Conditions/Anxiety/Pages/Treatment.aspx NICE (2017). First-choice antidepressant use in adults with depression or generalised anxiety disorder.
Adult colouring app, mindfulness, and anxiety 
Michail Mantzios, Hafsah Hussain, Amirah Hussain, Helen Egan, Paraic Scanlon
Retrieved from www.nice.org.uk/advice/ktt8/chapter/Evidence-context

Sandmire, D., Gorham, S., Rankin, N., \& Grimm, D. (2012). The influence of art making on anxiety: A pilot study. Art Therapy, 29, 68-73. https://doi.org/ 10.1080/07421656.2012.683748

Segal, Z. V., Williams, J. M. G., \& Teasdale, J. D. (2002). Mindfulness-based cognitive therapy for depression: $A$ new approach to preventing relapse. New York, NY: Guilford Press.

Small, S. R. (2006). Anxiety reduction: Expanding previous research on mandala coloring. Undergraduate Journal of Psychology, 19, 15-21.

Strauss, C., Cavanagh, K., Oliver, A., \& Pettman, D. (2014). Mindfulness-based interventions for people diagnosed with a current episode of an anxiety or depressive disorder: a meta-analysis of randomised controlled trials. PLoS One, 9, e96110. https://doi. org/10.1371/journal.pone.0096110

Stein, D. J., Hollander, E., \& Rothbaum, B. O. (2010). Textbook of anxiety disorders. Washington, DC: American Psychiatric Association Publishing.

Tanay, G., \& Bernstein, A. (2013). State Mindfulness Scale (SMS): Development and initial validation. Psychological Assessment, 25, 1286-1299. https:// doi.org/10.1037/a0034044

Vagnino, K. (2015). I tried a bunch of coloring apps, and they all miss the point. The Verge. Retrieved from www.theverge.com/2015/12/19/10622076/i-tried-abunch-ofcoloring-apps-and-they-all-miss-the-point Van der Vennet, R., \& Serice, S. (2012). Can colouring mandalas reduce anxiety? A replication study. Art Therapy, 29, 87-92. https://doi.org/10.1080/074216 56.2012 .68004

Vøllestad, J., Nielsen, M. B., \& Nielsen, G. H. (2012). Mindfulness-and acceptance-based interventions for anxiety disorders: A systematic review and meta-analysis. British Journal of Clinical Psychology, 51, 239-260. https://doi.org/10.1111/j.2044-8260. 2011.02024.x 